\title{
Quasi-16-day period oscillations observed in middle atmospheric ozone and temperature in Antarctica
}

\author{
T. D. Demissie ${ }^{1,2}$, N. H. Kleinknecht ${ }^{1}$, R. E. Hibbins ${ }^{1,2}$, P. J. Espy ${ }^{1,2}$, and C. Straub ${ }^{1}$ \\ ${ }^{1}$ Norwegian University of Science and Technology (NTNU), Trondheim, Norway \\ ${ }^{2}$ Birkeland Centre for Space Science, Bergen, Norway
}

Correspondence to: T. D. Demissie (teferi.demissie@ntnu.no)

Received: 6 February 2013 - Revised: 20 June 2013 - Accepted: 27 June 2013 - Published: 30 July 2013

\begin{abstract}
Nightly averaged mesospheric temperature derived from the hydroxyl nightglow at Rothera station $\left(67^{\circ} 34^{\prime} \mathrm{S}, 68^{\circ} 08^{\prime} \mathrm{W}\right)$ and nightly midnight measurements of ozone mixing ratio obtained from Troll station $\left(72^{\circ} 01^{\prime} \mathrm{S}\right.$, $2^{\circ} 32^{\prime} \mathrm{E}$ ) in Antarctica have been used to investigate the presence and vertical profile of the quasi-16-day planetary wave in the stratosphere and mesosphere during the Antarctic winter of 2009. The variations caused by planetary waves on the ozone mixing ratio and temperature are discussed, and spectral and cross-correlation analyses are performed to extract the wave amplitudes and to examine the vertical structure of the wave from 34 to $80 \mathrm{~km}$. The results show that while planetary-wave signatures with periods 3-12 days are strong below the stratopause, the oscillations associated with the 16day wave are the strongest and present in both the mesosphere and stratosphere. The period of the wave is found to increase below $42 \mathrm{~km}$ due to the Doppler shifting by the strong eastward zonal wind. The 16-day oscillation in the temperature is found to be correlated and phase coherent with the corresponding oscillation observed in $\mathrm{O}_{3}$ volume mixing ratio at all levels, and the wave is found to have vertical phase fronts consistent with a normal mode structure.
\end{abstract}

Keywords. Meteorology and Atmospheric Dynamics (Middle atmosphere dynamics; Waves and tides)

\section{Introduction}

In the past few decades, a number of studies using groundbased and satellite-borne systems as well as modelling studies have reported quasi-16-day period planetary waves (PWs) in the mesosphere (Manson et al., 1978; Vincent, 1990; Fritts et al., 1999; Miyoshi, 1999). A majority of the studies suggest that the PWs appearing in the mesosphere are due to the vertical propagation from the troposphere and stratosphere when the stratospheric zonal winds are weak and westerly (Charney and Drazin, 1961; Salby, 1981; Forbes et al., 1995; Lawrence and Jarvis, 2001). Other studies suggest that PWs can be generated in situ in the mesosphere by gravity wave breaking (Smith, 2003), or transported from the winter mesosphere across the equator (Forbes et al., 1995; Espy et al., 1997; Smith, 2003; Riggin et al., 2006; Hibbins et al., 2009). Espy et al. (1997) have further suggested that the QBO modulation of the appearance of the 16-day wave in the summer supports the inter-hemisphere transport hypothesis of Forbes et al. (1995). All the aforementioned studies indicate that the propagation and interaction of PWs with the atmosphere is not yet fully understood, and hence there is a need for further study supported by observations with uninterrupted vertical and temporal coverage.

The observational evidence for 16-day PWs in the mesosphere was first reported using meteor radar winds by Kingsley et al. (1978). Subsequent studies using wind measurements (e.g. Williams and Avery, 1992; Forbes et al., 1995; Mitchell et al., 1999; Luo et al., 2000; Jiang et al., 2005; Das et al., 2010) and temperature measurements (e.g. Espy and Witt, 1996; Espy et al., 1997) confirmed the existence of a quasi-16-day $\mathrm{PW}$ in the mesosphere. More recently, satellite data have been used to study the wave throughout the stratosphere and mesosphere (e.g. McDonald et al., 2011; Day et al., 2011).

In this study, we use continuous ground-based measurements of ozone mixing ratio profiles recorded with a microwave radiometer located at Troll station, Antarctica $\left(72^{\circ} 01^{\prime} \mathrm{S}, 2^{\circ} 32^{\prime} \mathrm{E}\right)$. Middle atmospheric $\mathrm{O}_{3}$ has been shown to vary out of phase with temperature (Finger et al., 1995; 
Belova et al., 2009) and hence can be used to trace and characterize the vertical phase structure of temperature perturbations caused by PWs. These observations are compared with concurrent ground-based mesopause airglow temperature data recorded at Rothera station Antarctica $\left(67^{\circ} 34^{\prime} \mathrm{S}\right.$, $68^{\circ} 08^{\prime} \mathrm{W}$ ) in order to determine the PW source regions and their evolution in time and altitude throughout the Antarctic winter. The temperature and $\mathrm{O}_{3}$ measurements used in this study span from 1 July 2009 to 21 September 2009. The PW signatures at different altitudes in Antarctica during winter of 2009 are identified and compared using spectral techniques.

\section{Measurement, analysis and results}

This study uses data acquired by the ground-based microwave radiometer of the British Antarctic Survey (BAS radiometer). The instrument was operated from the Norwegian Polar Institute's Troll research station in Antarctica between February 2008 and January 2010. Spectra in the region of the rotational transitions centred at $250.796 \mathrm{GHz}$ (nitric oxide, $\mathrm{NO}$ ), $249.79 \mathrm{GHz}$ and $249.96 \mathrm{GHz}$ (ozone, $\mathrm{O}_{3}$ ) and $230.538 \mathrm{GHz}$ (carbon monoxide, $\mathrm{CO}$ ) have been observed. A detailed description of the instrument is given in Espy et al. (2006) and Straub et al. (2013). Here we use $\mathrm{O}_{3}$ volume mixing ratio (vmr) profiles retrieved from one-hour averaged $\mathrm{O}_{3}$ spectra centred around midnight local time recorded between July and September 2009. These profiles cover an altitude range of approximately 34 to $80 \mathrm{~km}$ with an altitude resolution of the order of $10 \mathrm{~km}$ below $70 \mathrm{~km}$ and only column information above that level. A complete description of the optimal estimation retrieval technique (Rodgers, 1976) as applied to these data may be found in Kleinknecht (2010). Briefly, the a priori pressure, temperature, water vapour and ozone values used for the inversion below $45 \mathrm{~km}$ were derived from monthly mean ERA-40 profiles (Uppala et al., 2005). Between 45 and $85 \mathrm{~km}$, monthly mean temperature and pressure values were taken from the MSIS-00 model (Picone et al., 2002), and ozone and water vapour were taken from the US Standard Atmosphere Supplements (1966) for winter and summer conditions. For the wave studies here, the $\mathrm{O}_{3}$ a priori above $85 \mathrm{~km}$ were held at a constant value so as to ensure that the a priori did not induce oscillations. However, the strong dominance of the a priori at high and low altitudes could artificially reduce the amplitude of any oscillations present in the data there.

In addition to $\mathrm{O}_{3}$ measurements, this study uses temperature data obtained from a Michelson interferometer at the British Antarctic survey station at Rothera. Hydroxyl nightglow spectra measured by the interferometer were used to derive the rotational temperature from an emitting height centred around $87 \mathrm{~km}$ with a thickness of $8 \mathrm{~km}$ (Baker and Stair, 1988). The method of fitting the rotational temperature to the measured spectra is discussed in Espy and Hammond (1995). Here we used a night-time average of the

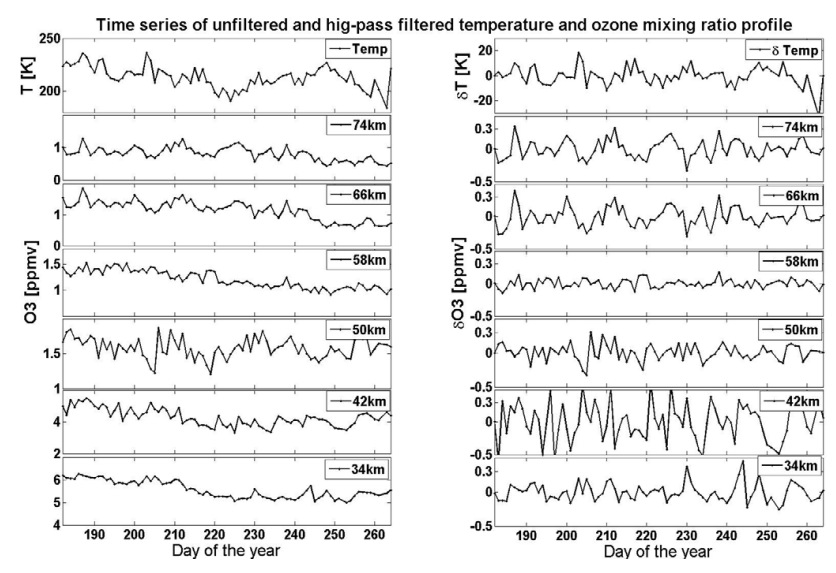

Fig. 1. Time series of temperature at $87 \mathrm{~km}$ (top panel) and the ozone mixing ratio at selected altitude levels (lower 6 panels). Left: raw (unfiltered) data; right: filtered data.

temperature extracted from the $\mathrm{OH}$ Meinel $(3,1)$ band. The weighted mean temperature was calculated for nights which have at least $2 \mathrm{~h}$ of data. There are no gaps in the data series used in the analysis period presented in this study.

Nightly averages of temperature and one hour average around midnight values of $\mathrm{O}_{3} \mathrm{vmr}$ were used to reduce the contribution to the measurements from periodic oscillations less than a day such as photolysis effects and other high frequency signals. Although the hourly averaged $\mathrm{O}_{3} \mathrm{vmr}$ around midnight was used, the analysis using the average of all values at solar zenith angles greater than 100 degrees gave similar results. A high-pass filter was applied to both datasets to filter out seasonal and long-period oscillations while retaining periodic motions with periods less than 20 days. A Butterworth IIR high-pass filter was specifically used to remove these long-period variations since it has a maximum flat frequency response in the selected pass band (e.g. Stearns, 1975). Figure 1 depicts the time series of unfiltered (left panel) and high-pass filtered (right panel) data of the temperature at $87 \mathrm{~km}$ and the $\mathrm{O}_{3} \mathrm{vmr}$ at six selected altitudes ( $34 \mathrm{~km}, 42 \mathrm{~km}, 50 \mathrm{~km}, 58 \mathrm{~km}, 66 \mathrm{~km}$ and $74 \mathrm{~km}$ ). Note that the high-pass filtered datasets have similar features and peaks as that of the raw data. Wave patterns can easily be identified by eye in the vertical profile of the $\mathrm{O}_{3}$ data and the temperature at $87 \mathrm{~km}$, and spectral techniques can be used to identify the significant periods in the time series.

A fast Fourier transform (FFT) was performed on the highpass filtered datasets to determine the amplitude and phase of periodic fluctuations observed in the $\mathrm{O}_{3}$ and temperature with periods of less than 20 days. A Hamming window (Nuttall, 1981) was applied to the data before the FFT was performed in order to reduce spectral leakage and side-lobe effects on the FFT. Figure 2 presents the spectra of the oscillations in the high-pass filtered temperature (top panel) and $\mathrm{O}_{3}$ vmr (bottom panel) in the altitude range from 34 to $80 \mathrm{~km}$ that resulted from the FFT. The amplitude spectra 

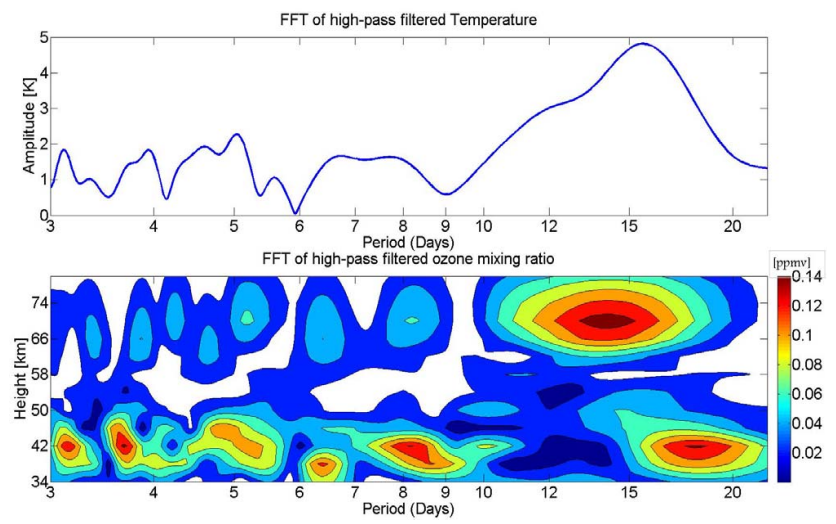

Fig. 2. FFT of the high-pass filtered temperature at $87 \mathrm{~km}$ (top panel) and $\mathrm{O}_{3} \mathrm{vmr}$ profile (bottom panel) in Antarctica during winter 2009.

(the absolute value of the power spectra) of the temperature and the $\mathrm{O}_{3} \mathrm{vmr}$ profiles show a number of oscillations with periods in the 3-20-day range. The power-spectral analysis shows that the amplitude of oscillations in the range between 12 and 20 days is the strongest and present throughout the stratosphere and mesosphere in the ozone, and also in the $\mathrm{OH}$ temperature around the mesopause $(87 \mathrm{~km})$. A closer look at the wave period of the dominant oscillation in this range shows that the central period of the peak power varies with altitude between 14 and 18 days in the $\mathrm{O}_{3} \mathrm{vmr}$ and appears around 16 days with an amplitude of $5 \mathrm{~K}$ in the $\mathrm{OH}$ airglow temperature. This oscillation is most likely associated with the quasi-16-day PW with zonal wave number 1, which has often been observed in mesospheric wind measurements (e.g. Das et al., 2010) and temperature measurements (e.g. Day et al., 2011). It is evident in Fig. 2 that there are also strong wave features below the stratopause at a range of shorter periods. All the wave activity diminishes around the stratopause. The strongest wave activity that reappears above the stratopause is in the range between 12 and 20 days. The other shorter period waves that are seen in the stratosphere are clearly much weaker in the mesosphere.

To examine whether or not the 16-day oscillations observed in the mesopause temperature and $\mathrm{O}_{3} \mathrm{vmr}$ profiles are correlated and phase coherent, a cross-spectral analysis was performed between the two datasets. Figure 3 shows the cross spectrum between the temperature at $87 \mathrm{~km}$ and each level of the $\mathrm{O}_{3} \mathrm{vmr}$ as a function of period in days. The cross spectra show that despite the low amplitudes in the FFT, there are oscillations at each altitude at a nominal period of 16 days that are coherent in phase with the same period oscillation in the temperature near $87 \mathrm{~km}$, and this indicates a physical connection between the two. On the other hand, there is little or no coherency between the oscillations of the shorter periods in the ozone and the temperature oscillation at $87 \mathrm{~km}$.

Having documented the presence of the quasi-16-day wave in the data through both the power and cross-spectral

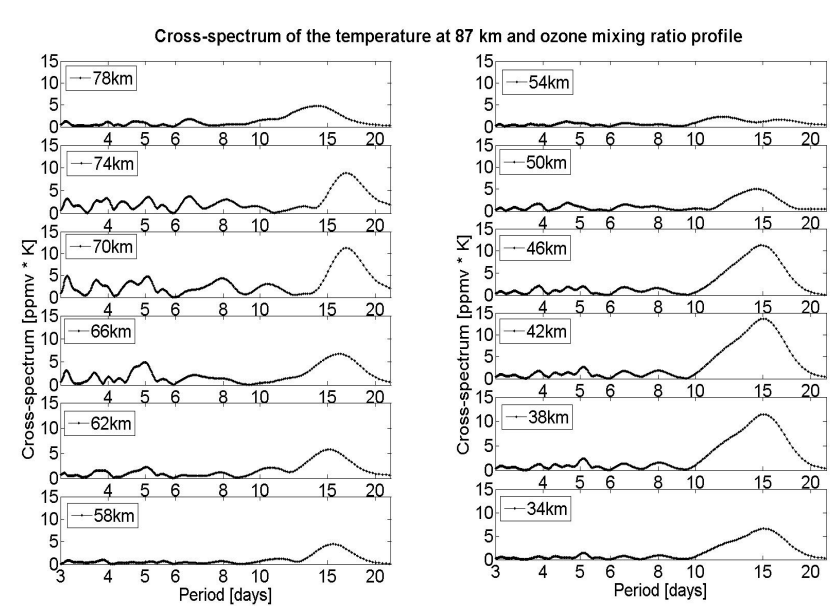

Fig. 3. Cross spectrum of the temperature at $87 \mathrm{~km}$ and $\mathrm{O}_{3}$ vmr profile for winter 2009 in Antarctica for different levels in the stratosphere and mesosphere.

analysis, the periodic range of the wave is isolated using a band-pass filter in order to examine the vertical structure of the phase fronts and to quantify the coherence of the quasi16-day wave. The temperature and $\mathrm{O}_{3} \mathrm{vmr}$ data were bandpass filtered between 12-20 day periods, and a time-lagged cross-correlation analysis was performed on the two datasets. The choice of this range for the band-pass filter was to isolate the wave activity observed in the spectra shown in Fig. 2, and is consistent with the band-pass range used in previous 16day PW studies (e.g. Luo et al., 2002; Day et al., 2011). The left panel of Fig. 4 shows the time-lagged cross correlation between the temperature at $87 \mathrm{~km}$ and each level of $\mathrm{O}_{3} \mathrm{vmr}$ as a function of height and time lag in days. The colour scale in the figure represents the intensity of the correlation, which indicates how much of the $\mathrm{O}_{3}$ variance at each altitude can be explained by the temperature fluctuations. At zero lag, there are regions with significant anti-correlation between the temperature at $87 \mathrm{~km}$ and the $\mathrm{O}_{3} \mathrm{vmr}$ within the altitude range from 34 to $80 \mathrm{~km}$. At altitudes above $65 \mathrm{~km}$ and below $55 \mathrm{~km}$, this zero-lag reaches a maximum anti-correlation of approximately -0.8 , and these values are statistically significant at the $95 \%$ confidence level. Near the stratopause, in the region where the FFT and cross-spectral amplitudes were low, the cross correlation is nearly zero and not statistically significant. The right panel of Fig. 4 shows the phase change between the temperature and $\mathrm{O}_{3} \mathrm{vmr}$ at different altitudes along the line of maximum anti-correlation nearest to zero lag. Only the anti-correlation values whose significance is above $95 \%$ are plotted. The phase change between the temperature and $\mathrm{O}_{3} \mathrm{vmr}$ show that there is little vertical tilt of the phase fronts with altitude above $38 \mathrm{~km}$ indicating a normal mode structure. However, it should be noted that phase fronts above $70 \mathrm{~km}$ are nearly vertical largely because of the poorer altitude resolution of the $\mathrm{O}_{3} \mathrm{vmr}$ above that altitude. 


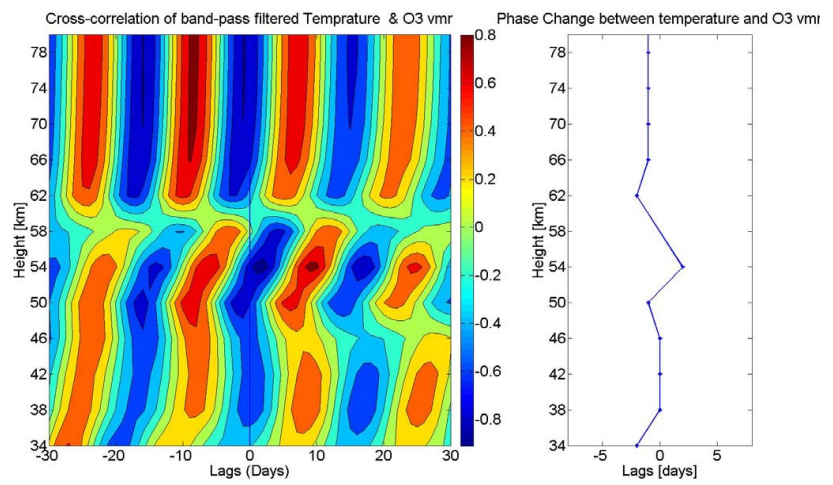

Fig. 4. Left panel: the time-lagged cross correlation between winter mesospheric temperature and ozone at different levels. Red colour represents correlation and blue denotes anti-correlation. Right panel: vertical profile of phase change between temperature and $\mathrm{O}_{3}$ vmr. These phases are all \pm 0.5 days.

\section{Discussion and conclusion}

The purpose of this study was to use temporal variations in the mesopause airglow temperatures and the $\mathrm{O}_{3} \mathrm{vmr}$ profiles in the mesosphere and stratosphere to trace and characterize the vertical behaviour of planetary waves reaching the mesopause during the winter. The results from the powerspectral analysis in Sect. 2 show the largest amplitudes for the quasi-16-day oscillation in both the temperature and $\mathrm{O}_{3}$ fields in the wintertime over Antarctica. We find that the period of the wave ranges from 14-18 days in the mesosphere and stratosphere, consistent with previous observations (e.g. Luo et al., 2002; Williams and Avery, 1992). The wave period is observed to shift systematically to longer periods below the stratopause, reaching $\sim 18$ days below $42 \mathrm{~km}$. This suggests that the wave is interacting with the rapidly increasing eastward winds at these altitudes (Hibbins et al., 2005) and Doppler shifting to longer periods as reported by Forbes (1995).

Unlike the oscillations with periods 3-12 days, which the power-spectral analysis shows are mostly confined below the stratopause, the quasi-16-day wave shows large amplitudes above and below the stratopause. The amplitude of the wave decreases markedly close to the stratopause. This may be due to the high negative wind shears above $45 \mathrm{~km}$ altering the index of refraction of the planetary wave as has been suggested by McDonald et al. (2011) based on EOS MLS temperature data. However, we cannot rule out that this decrease of amplitude is merely due to low $\mathrm{O}_{3} \mathrm{vmr}$ values that minimise near this altitude. Similarly, the sharp fall off of wave amplitudes at the upper and lower altitudes seen in Fig. 2 is likely due to the large a priori contribution to the retrieved $\mathrm{O}_{3}$ at these altitudes. The nearly constant a priori values will tend to minimise the wave-induced departures from this profile, reducing the extracted wave amplitudes.
The cross-spectral analysis shows that the 16-day wave observed in the temperature fluctuations around $87 \mathrm{~km}$ at Rothera is related and phase coherent with the 16-day wave observed in the $\mathrm{O}_{3}$ vmr data at all levels from $34-80 \mathrm{~km}$ at Troll station. The vertical variation of the cross-spectral amplitude is a reflection of the variation in the power spectral amplitudes. However, the observed phase-coherency indicates that the 16-day wave observed in both the temperature and the $\mathrm{O}_{3} \mathrm{vmr}$ data have a physical connection and could be driven by the same source.

Once the phase-coherent oscillations with periods corresponding to the 16-day wave were identified in the temperature and $\mathrm{O}_{3} \mathrm{vmr}$ at each altitude, the wave was isolated using a band-pass filter and the lagged cross correlation between the two datasets was performed. This was done to quantify the coherence and examine the relative phase between the 16-day oscillations in temperature at $87 \mathrm{~km}$ and those in the $\mathrm{O}_{3} \mathrm{vmr}$ at each altitude below. The cross-correlation analysis displayed in the left panel of Fig. 4 shows that at zero lag, the temperature fluctuations close to $87 \mathrm{~km}$ are anti-correlated with the $\mathrm{O}_{3} \mathrm{vmr}$ at levels between $34 \mathrm{~km}$ to $80 \mathrm{~km}$. This anticorrelation is expected due to the temperature dependency of the $\mathrm{O}_{3}$ reaction in the upper stratosphere and mesosphere. There, the chemical lifetime of $\mathrm{O}_{3}$ is much shorter than the transport timescales. As a result, variations in temperature caused by PWs drive the reactions nonlinearly and cause corresponding changes in the $\mathrm{O}_{3}$ concentration. The inverse temperature dependence of the $\mathrm{O}_{3}$ production reactions lead to a negative correlation (or an anti-correlation) between the $\mathrm{O}_{3}$ and temperature fluctuations (Finger et al., 1995; Huang et al., 2008; Belova et al., 2009). The magnitudes of the correlation coefficient minimise near the stratopause, where the power spectral amplitudes are also a minimum. As a result, the correlation values are not statistically significant at $58 \mathrm{~km}$. However, at all other altitudes the anti-correlations are statistically significant above the $95 \%$ confidence level, ranging from -0.5 to -0.8 , showing that the phase-coherent, 16-day variations in mesopause temperature and middle atmospheric $\mathrm{O}_{3}$ are statistically significant.

The phase change between the temperature and $\mathrm{O}_{3} \mathrm{vmr}$ at different altitudes was determined by extracting the minimum correlation value (maximum anti-correlation) nearest to zero lag. These phase fronts, displayed in the right panel of Fig. 4, show little vertical tilt with altitude above $38 \mathrm{~km}$, indicating a normal mode structure. Although the magnitude of the correlation coefficient is observed to be small and insignificant near the stratopause, whether by instrumental or index of refraction effects (McDonald et al., 2011), we see here that the wave is not completely absorbed and is able to continue above this region. The nearly vertical phase fronts above $70 \mathrm{~km}$ are likely a consequence of the coarse altitude resolution of the $\mathrm{O}_{3} \mathrm{vmr}$ data there smoothing any vertical structure. However, we note that there are several observations of the high-latitude southern hemisphere winter 16-day wave in radar wind data that show that the wave continues 
above $80 \mathrm{~km}$ as a normal mode until it reaches the critical level caused by the wind reversal from east to west near $95 \mathrm{~km}$ (e.g. Espy et al., 2005).

In conclusion, we have presented measurements of wintertime 16-day oscillations in both the $\mathrm{O}_{3} \mathrm{vmr}$ above Troll station, Antarctica, from a ground-based microwave radiometer and in the temperature from hydroxyl night glow above Rothera, Antarctica. Power-spectral analysis found that periods around 16 days had the largest amplitudes in both datasets. In the $\mathrm{O}_{3}$ data, waves with periods 3-12 days were also strong below the stratopause, but only the 16 day wave persisted into the mesosphere. In addition, the period of the 16-day wave increased below $42 \mathrm{~km}$ due to Doppler shifting by the increasing eastward zonal winds. The amplitude of the quasi-16-day wave was also found to vary with height, diminishing at the highest and lowest altitudes due to instrumental effects. However, the minimum amplitudes found near the stratopause could be due either to wave absorption by the large negative wind gradients or to the minimum $\mathrm{O}_{3}$ concentrations found there. Despite the presence of low wave amplitudes, the 16-day oscillations in the temperature are correlated and phase-coherent with the corresponding oscillations observed in $\mathrm{O}_{3} \mathrm{vmr}$ at all levels. The 16-day wave is found to have vertical phase fronts consistent with a normal mode structure, and extends from the mesopause down into the upper stratosphere. Thus, utilizing a ground-based radiometer, with its high temporal resolution allows one to extend radar measurements of PWs from their lower measurements limits, $\sim 80 \mathrm{~km}$, down to $\sim 34 \mathrm{~km}$. In this way, the vertical phase structure and interaction with the background wind can be quantified throughout the mesosphere and upper stratosphere.

Acknowledgements. We thank David Newnham at BAS, Kim Holmén at the Norwegian Polar Institute (NPI) and Paul Hartogh at Max Planck Institute (MPI) for their support of the microwave radiometer. We also thank Asbjørn Djupdal (NPI), David Maxfield and Paul Breen (BAS) for their help. The work has been funded by the Norwegian Research council (NFR) project "Gravity-wave sources and scales in the Polar Regions and their effect on Polar Mesospheric Clouds". In addition, we acknowledge the Norwegian Polar Institute Antarctic Program which provided funding for Corinne Straub under the project "Observations of carbon monoxide and ozone in the Antarctic and Arctic: Implications for the Inter-hemispheric coupling of vertical motions".

Topical Editor C. Jacobi thanks C. Meek and one anonymous referee for their help in evaluating this paper.

\section{References}

Baker, D. J. and Stair, J. T.: Rocket measurements of the altitude distributions of the hydroxyl airglow, Phys. Scripta., 37, 611622, 1988.

Belova, A., Kirkwood, S., and Murtagh, D.: Planetary waves in ozone and temperature in the Northern Hemisphere winters of 2002/2003 and early 2005, Ann. Geophys., 27, 1189-1206, doi:10.5194/angeo-27-1189-2009, 2009.

Charney, J. G. and Drazin, P. G.: Propagation of planetary-scale disturbances from lower into the upper atmosphere, J. Geophys. Res., 66, 83-109, 1961.

Das, S. S., Kumar, K. K., Veena, S. B., and Ramkumar, G.: Simultaneous observation of quasi 16 day Wave in the mesospheric winds and temperature over low latitudes with the SKiYMET radar, Radio Sci., 45, RS6014, doi:10.1029/2009RS004300, 2010.

Day, K. A., Hibbins, R. E., and Mitchell, N. J.: Aura MLS observations of the westward-propagating $s=1$, 16-day planetary wave in the stratosphere, mesosphere and lower thermosphere, Atmos. Chem. Phys., 11, 4149-4161, doi:10.5194/acp-11-41492011, 2011.

Espy, P. J. and Hammond, M. R.: Atmospheric transmission coefficients for hydroxyl rotational lines used in rotational temperature determinations, J. Quant. Spectosc. Ra., 54, 879-889, 1995.

Espy, P. J. and Witt, G.: Observation of a quasi 16-day oscillation in the polar summer mesospheric temperature, Geophys. Res. Lett., 23, 1071-1074, 1996.

Espy, P. J., Stegman, J., and Witt, G.: Interannual variations of the quasi-16-day oscillation in the polar summer mesospheric temperature, J. Geophys. Res., 102, 1983-1990, 1997.

Espy, P. J., Hibbins, R. E., Riggin, D. M., and Fritts, D. C.: Mesospheric planetary waves over Antarctica during 2002, Geophys. Res. Lett., 32, L21804, doi:10.1029/2005GL023886, 2005.

Espy, P. J., Hartogh, P., and Holmén, K.: A microwave radiometer for the remote sensing of nitric oxide and ozone in the middle atmosphere, Remote Sensing of Clouds and the Atmosphere XI, Proc. of SPIE, Vol. 6362, 63620P1-63620P9, doi:10.1117/12.688953, 2006.

Finger, F. G., Nagatani, R. M., Gelman, M. E., Long, C. S., and Miller, A. J.: Consistency between variations of ozone and temperature in the stratosphere, Geophys. Res. Lett., 22, 3477-3480, 1995.

Forbes, J. M.: Tidal and planetary waves, in The Upper Mesosphere and Lower Thermosphere: A Review of Experiment and Theory, Geophys. Monogr. Ser., Vol. 87, 67-87, AGU, Washington, DC, doi:10.1029/GM087p0067, 1995.

Forbes, J. M., Hagan, M. E., Miyahara, S., Vial, F., Manson, A. H., Meek, C. E., and Portnyagin, Y. I.: Quasi-16-day oscillation in the mesosphere and lower thermosphere, J. Geophys. Res., 100, 9149-9163, 1995.

Fritts, D. C., Isler, J. R., Lieberman, R. S., Burrage, M. D., Marsh, D. R., Nakamura, T., Tsuda, T., Vincent, R. A., and Reid, I. M.: Two-day wave structure and mean flow interactions observed by radar and High Resolution Doppler Imager, J. Geophys. Res., 104, 3953-3970, 1999.

Hibbins, R. E., Shanklin, J. D., Espy, P. J., Jarvis, M. J., Riggin, D. M., Fritts, D. C., and Lübken, F.-J.: Seasonal variations in the horizontal wind structure from $0-100 \mathrm{~km}$ above Rothera station, Antarctica $\left(67^{\circ} \mathrm{S}, 68^{\circ} \mathrm{W}\right)$, Atmos. Chem. Phys., 5, 2973-2980, 
doi:10.5194/acp-5-2973-2005, 2005.

Hibbins, R. E., Jarvis, M. J., and Ford, E. A. K.: Quasi-biennial oscillation influence on long-period planetary waves in the Antarctic upper mesosphere, J. Geophys. Res., 114, D09109, doi:10.1029/2008JD011174, 2009.

Huang, F. T., Mayr, H. G., Reber, C. A., Russell III, J. M., Mlynczak, M. G., and Mengel, J. G.: Ozone quasi-biennial oscillations (QBO), semiannual oscillations (SAO), and correlations with temperature in the mesosphere, lower thermosphere, and stratosphere, based on measurements from SABER on TIMED and MLS on UARS, J. Geophys. Res., 113, A01316, doi:10.1029/2007JA012634, 2008.

Jiang, G.-Y., Xiong, J.-G., Wan, W.-X., Ning, B.-Q., Liu, L.-B., Vincent, R. A., and Reid, I. M.: The 16-day waves in the mesosphere and lower thermosphere over Wuhan $\left(30.6^{\circ} \mathrm{N}, 114.5^{\circ} \mathrm{E}\right)$ and Adelaide ( $35^{\circ} \mathrm{S}, 138^{\circ}$ E), Adv. Space Res., 35, 2005-2010, 2005.

Kingsley, S. P., Muller, H. G., Nelson, L., and Scholefield, A.: Meteor winds over Sheffield, J. Atmos. Terr. Phy., 40, 917-922, 1978.

Kleinknecht, N. H.: Planetary Wave Oscillations Observed in Ozone from Troll Station Antarctica, M.Sc. thesis, Norwegian University of Science and Technology (NTNU), Trondheim, Norway, 2010.

Lawrence, A. R. and Jarvis, M. J.: Initial comparisons of planetary waves in the stratosphere, mesosphere and ionosphere over Antarctica, Geophys. Res. Lett., 28, 203-206, 2001.

Luo, Y., Manson, A. H., Meek, C. E., Meyer, C. K., and Forbes, J. M.: Quasi 16-day oscillations in the mesosphere and lower thermosphere at Saskatoon $\left(52^{\circ}\right.$ N, $107^{\circ}$ W), 1980-1996, J. Geophys. Res., 105, 2125-2138, 2000.

Luo, Y., Manson, A. H., Meek, C. E., Thayaparan, T., MacDougall, J., and Hocking, W. K.: The 16-day wave in the mesosphere and the lower thermosphere: simultaneous observations at Saskatoon $\left(52^{\circ} \mathrm{N}, 107^{\circ} \mathrm{W}\right)$, London $\left(43^{\circ} \mathrm{N}, 81^{\circ} \mathrm{W}\right)$, Canada, J. Atmos. Sol.-Terr. Phy., 64, 1287-1307, 2002.

McDonald, A. J., Hibbins, R. E., and Jarvis, M. J.: Properties of the quasi-16 day wave derived from EOS MLS observations, J. Geophys. Res., 116, D06112, doi:10.1029/2010JD014719, 2011

Manson, A. H., Gregory, J. B., Meek, C. E., and Stephenson, D.: Wind and wave motions to $110 \mathrm{~km}$ at midlatitudes, J. Atmos. Sci., 32, 831-836, 1978.

Mitchell, N. J., Middleton, H. R., Beard, A. G., Williams, P. J. S., and Muller, H. G.: The 16-day planetary wave in the mesosphere and lower thermosphere, Ann. Geophys., 17, 1447-1456, doi:10.1007/s00585-999-1447-9, 1999.

Miyoshi, Y.: Numerical simulation of the 5-day and 16-day waves in the mesopause region, Earth Planets Space, 51, 763-772, 1999.
Nuttall, A. H.: Some windows with very good sidelobe behavior, IEEE T. Acoust. Speech, 29, 84-91, 1981.

Picone, J. M., Hedin, A. E., Drob, D. P., and Aikin, A. C.: NRLMSISE-00 empirical model of the atmosphere: Statistical comparisons and scientific issues, J. Geophys. Res., 107, 1468, doi:10.1029/2002JA009430, 2002

Riggin, D. M., Liu, H.-L., Lieberman, R. S., Roble, R. G., Russell III, J. M., Mertens, C. J., Mlynczak, M. G., Pancheva, D., Franke, S. J., Murayama, Y., Manson, A. H., Meek, C. E., and Vincent, R. A.: Observations of the 5-day wave in the mesosphere and lower thermosphere, J. Atmos. Sol-Terr. Phy., 68, 323-329, 2006.

Rodgers, C.: Retrieval of atmospheric temperature and composition from measurements of thermal radiation, Rev. Geophys. Space Phys., 14, 609-624, 1976.

Salby, M. L.: Rossby normal modes in nonuniform background configuration. Part II: Equinox and solstice conditions, J. Atmos. Sci., 38, 1827-1840, 1981.

Smith, A. K.: The origin of stationary planetary waves in the upper mesosphere. J. Atmos. Sci., 60, 3033-3041, 2003.

Stearns, S. D.: Digital signal analysis, Hayden book, Rochelle Park, New Jersey, 1975.

Straub, C., Espy, P. J., Hibbins, R. E., and Newnham, D. A.: Mesospheric CO above Troll station, Antarctica observed by a ground based microwave radiometer, Earth Syst. Sci. Data, 5, 199-208, doi:10.5194/essd-5-199-2013, 2013.

Uppala, S. M., Kållberg, P. W., Simmons, A. J., Andrae, U., Da Costa Bechtold, V., Fiorino, M., Gibson J. K., Haseler, J., Hernandez, A., Kelly, G. A., Li, X., Onogi, K., Saarinen, S., Sokka, N., Allan, R. P., Andersson, E., Arpe, K., Balmaseda, M. A., Beljaars, A. C. M., Van De Berg, L., Bidlot, J., Bormann, N., Caires, S., Chevallier, F., Dethof, A., Dragosavac, M., Fisher, M., Fuentes, M., Hagemann,S., Hólm, E., Hoskins, B. J., Isaksen, L., Janssen, P. A. E. M., Jenne, R., McNally, A. P., Mahfouf, J.-F., Morcrette, J.-J., Rayner, N. A., Saunders, R. W., Simon, P., Sterl, A., Trenberth, K. E., Untch, A., Vasiljevic, D., Viterbo, P., and Woollen, J.: The ERA-40 re-analysis, Q. J. Roy. Meteorol. Soc., 131, 2961-3012, doi:10.1256/qj.04.176, 2005.

US Standard Atmosphere Supplements: U.S. Government Printing Office, Washington, DC, 1966.

Vincent, R. A.: Planetary and gravity waves in the mesosphere and lower thermosphere, Adv. Space Res., 10, 93-101, 1990.

Williams, C. R. and Avery, S. K.: Analysis of long-period waves using the mesosphere-stratosphere-troposphere radar at poker flats, Alaska, J. Geophys. Res., 97, 20855-20861, 1992. 